\title{
Immune Responses Induced by HSP60 DNA Vaccine against Toxoplasma gondii Infection in Kunming Mice
}

\author{
Zhong-Yuan $\mathrm{Li}^{1,2}$, Jing Lư ${ }^{3}$, Nian-Zhang Zhang ${ }^{2}$, Jia Chen ${ }^{4}$, Xing-Quan Zhu ${ }^{2,5, *}$ \\ College of Animal Science and Technology, Anhui Agricultural University, Hefei, Anhui Province 230036, P. R. China; ${ }^{2}$ State Key Laboratory of \\ Veterinary Etiological Biology, Key Laboratory of Veterinary Parasitology of Gansu Province, Lanzhou Veterinary Research Institute, Chinese \\ Academy of Agricultural Sciences, Lanzhou, Gansu Province 730046, P. R. China; ${ }^{3}$ Guangdong Wens Dahuanong Biotechnology Co., Ltd, Yunfu, \\ Guangdong Province 524700, P. R. China; ${ }^{4}$ Ningbo University School of Medicine, Ningbo, Zhejiang Province 315211, P. R. China; ${ }^{5}$ Jiangsu \\ Co-innovation Center for the Prevention and Control of Important Animal Infectious Diseases and Zoonoses, Yangzhou University College of \\ Veterinary Medicine, Yangzhou, Jiangsu Province 225009, P. R. China
}

\begin{abstract}
Toxoplasma gondii can infect all the vertebrates including human, and leads to serious toxoplasmosis and considerable veterinary problems. T. gondii heat shock protein 60 (HSP60) is associated with the activation of antigen presenting cells by inducing initial immune responses and releasing inflammatory cytokines. It might be a potential DNA vaccine candidate for this parasite. A pVAX-HSP60 DNA vaccine was constructed and immune responses was evaluated in Kunming mice in this study. Our data indicated that the innate and adaptive immune responses was elicited by successive immunizations with pVAX-HSP60 DNA, showing apparent increases of CD3e+CD4+ and CD3e+CD8a+ T cells in spleen tissues of the HSP60 DNA-immunized mice $(24.70 \pm 1.23 \%$ and $10.90 \pm 0.89 \%, P<0.05)$ and higher levels of specific antibodies in sera. Furthermore, the survival period of the immunized mice $(10.53 \pm 4.78$ day) were significantly prolonged during the acute T. gondii infection. Decrease of brain cysts was significant in the experimental group during the chronic infection $(P<0.01)$. Taken together, TgHSP60 DNA can be as a vaccine candidate to prevent the acute and chronic T. gondii infections.
\end{abstract}

Key words: Toxoplasma gondii, HSP60 DNA, Kunming mouse, immune response

\section{INTRODUCTION}

Toxoplasma gondii is an important obligate intracellular parasitic protist that can virtually infect all the warm-blooded animals including humans, causing serious clinical diseases and noticeable veterinary problems especially for pregnant women and immunocompromised patients [1,2]. In addition, so far there are no ideal drugs for the therapy of toxoplasmosis [3]. Therefore, an effective and safe vaccine is urgently needed to prevent and control the infection of this parasite both in medical and veterinary circumstances.

Heat shock proteins (HSPs) with wide distribution are the highly conserved molecular chaperones, which can keep the proteins from mutation, misfolding, inaccurate modification,

- Received 9 February 2018, revised 1 April 2018, accepted 23 April 2018

*Corresponding author (xingquanzhu1@hotmail.com)

(c) 2018, Korean Society for Parasitology and Tropical Medicine

This is an Open Access article distributed under the terms of the Creative Commons Attribution Non-Commercial License (http://creativecommons.org/licenses/by-nc/4.0) which permits unrestricted non-commercial use, distribution, and reproduction in any

medium, provided the original work is properly cited. and the acute influence of environment or chronic insult etc; HSPs are consecutively expressed during the growth process of cell cycles and play an important regulatory role in the protein folding/refolding, repair, degradation and the intracellular transportation [4-6]. In addition to being consecutively induced, HSPs can be also triggered by a series of physiological, pathological or environmental factors and are relevant to various clinical diseases such as stress, infection, autoimmunity and cancer [7-9]. HSPs may have potentially experimental and/or clinical applications as the molecular biomarkers for etiological diagnosis, therapeutic targets for disease treatment, or vaccine candidates for epidemic prevention in animals and human beings.

As an important member of the HSP family, T. gondii HSP60 was located in mitochondria and acts as a molecular chaperone that participates in stage-specific induction in the respiratory pathway of this parasite, mediating the activation of antigen presenting cells by stimulating inflammatory factors and inducing initial immune responses, which suggests that HSP60 may be a good DNA vaccine candidate for the preven- 
tion and control of T. gondii $[10,11]$. In this study, pVAX-HSP60 DNA vaccine was constructed using pVAX I vector and its protective effects against the acute and chronic infections of $T$. gondii was evaluated in Kunming mouse.

\section{MATERIALS AND METHODS}

\section{Animals and ethics statement}

Six-week-old female Kunming mice of specific-pathogenfree (SPF) grade were used in the present study. Kunming mice have clear genetic backgrounds, immunological and hematological indexes, and are the most commonly used laboratory animals for biological and biochemical studies in China $[12,13]$. A number of previous studies have shown that Kunming mice are quite susceptible to $T$. gondii infection, and they serve as ideal model for vaccination studies against $T$. gondii infection [13]. Kunming mice were purchased from the Laboratory Animal Center, Lanzhou Institute of Biological Products (Lanzhou, China), and all the animal procedures in the study were approved by the Animal Ethics and Administration Committee of Lanzhou Veterinary Research Institute, Chinese Academy of Agricultural Sciences (Approval No. LVRIAEC2012-011).

\section{Parasites}

Two strains of T. gondii (RH and PRU) saved in the Parasitology Department of Lanzhou Veterinary Research Institute were used in the present study. RH tachyzoites (Type I) maintained by serial passage in African green monkey kidney (Vero) cell monolayers were collected, washed and re-suspended as described previously [13]. Cys ts of PRU strain (Type II) sustained through monthly passage were separated from brains of the orally infected female Kunming mice. The purified RH and PRU parasites were quantified for preparation of Toxoplasma lysate antigen (TLA) and challenge of immunized Kunming mice [13].

\section{Construction of recombinant plasmid}

Total RNA of $T$. gondii RH tachyzoites was extracted along the instruction of E.Z.N.A. ${ }^{\circledR}$ Total RNA Kit I (Omega Bio-Tek, Norcross, Georgia, USA) and used to construct pVAX-HSP60 DNA vaccine. A pair of specific primers (forward primer: 5'- GGGGTACCATGCTTGCCCGCGCTTCAGC-3'; reverse primer: 5'-AAGGAAAAAAGCGGCCGCCTAGTACATGCCTCCCATGCCGC-3') were designed to duplicate the full-length coding sequence of Toxoplasma HSP60 gene (GenBank XM_002367081), in which 2 restriction enzyme sites (KpnI and NotI) were underlined.
An RT-PCR amplification was performed as the guidance of PrimeScript ${ }^{\circledR}$ One Step RT-PCR Kit (Takara, Dalian, China): reverse transcription at $50.0^{\circ} \mathrm{C}$ for $30 \mathrm{~min}$; initial denaturation at $94.0^{\circ} \mathrm{C}$ for 2 min followed by 35 cycles composing of $94.0^{\circ} \mathrm{C}$ for $1 \mathrm{~min}, 60.4^{\circ} \mathrm{C}$ for $45 \mathrm{sec}$ and $72.0^{\circ} \mathrm{C}$ for $2 \mathrm{~min}$; the final extension step at $72.0^{\circ} \mathrm{C}$ for $10 \mathrm{~min}$. The products were purified and subsequently inserted into pMD18-T vector (Takara), forming pMD-HSP60 recombinant vector. The HSP60 sticky fragments were cut from pMD-HSP60 vector using KpnI and NotI, purified with gel extraction and subsequently inserted into the corresponding site of pVAX I vector through T4 DNA ligase (Takara), generating the recombinant plasmid pVAXHSP60. The concentration of pVAX-HSP60 was determined using spectrophotometer at OD260 and OD280. Sequence accuracy was further confirmed by PCR, DNA sequencing and double-enzyme digestion.

\section{Immunofluorescence}

Human embryonic kidney 293 cells (HEK293) were used to confirm that whether the HSP60 recombinant protein was expressed in eukaryotic cell as previous description [14]. In brief, HEK293 cells grown in 6-well plate were transfected with 10.0 $\mu \mathrm{g}$ pVAX-HSP60 endotoxin-free plasmid using lipofectamine 2000 (Invitrogen, Carlsbad, California, USA) as instructed by the manufacturer. Three days post-transfection, the samples were fixed, permeabilized, blocked and incubated with goat anti-Toxoplasma serum at $37.0^{\circ} \mathrm{C}$ and subsequently secondary antibody at room temperature (RT) with darkness for $60 \mathrm{~min}$. The dilutions of primary and secondary antibodies were as follows: the serum stored in our laboratory, 1:50; Alexa Fluor ${ }^{\circledR}$ 488-AffiniPure Donkey Anti-Goat IgG (H+L) (Jackson ImmunoResearch Laboratories Inc, West Grove, Pennsylvania, USA), 1:1,000. Group transfected with pVAX I vector was used as the control. The fluorescent images were recorded by fluorescence microscope (Olymplus IX 51, Olympus, Tokyo, Japan) with camera D7000 (Nikon, Tokyo, Japan).

\section{Immunization and challenge}

The female Kunming mice were randomly separated into 4 groups (42 mice per group, shown in Table 1), and their immunization and challenge were performed as the previous approaches with some modifications [15]. Three groups of Kunming mice were respectively immunized with $100 \mu \mathrm{g}$ pVAXHSP60, $100 \mu \mathrm{g}$ pVAX I or $100 \mu \mathrm{l}$ of sterile PBS for 3 times with 2-week interval (shown in Table 1). The rest group without 
Table 1. Details on immunization of Kunming mice

\begin{tabular}{|c|c|c|c|c|c|c|}
\hline Group & $\begin{array}{c}\text { Treatment } \\
\text { (of } 100 \mu \mathrm{l} \text { PBS) }\end{array}$ & $\begin{array}{c}\text { Total } \\
\text { sample size }\end{array}$ & $\begin{array}{c}\text { Route of } \\
\text { administration }\end{array}$ & $\begin{array}{c}\text { Mice } \\
\text { number in } \mathrm{Hl}^{\mathrm{a}}\end{array}$ & $\begin{array}{c}\text { Mice } \\
\text { number in } \mathrm{CIR}^{\mathrm{b}}\end{array}$ & $\begin{array}{c}\text { Mice number in } \\
\text { challenges }\end{array}$ \\
\hline I & Control & 42 & - & 12 & 3 & $15^{c}, 15^{d}$ \\
\hline$\|$ & $100 \mu \mathrm{PBS}$ & 42 & Thigh muscle & 12 & 3 & $15^{c}, 15^{d}$ \\
\hline III & 100 ug pVAX I & 42 & Thigh muscle & 12 & 3 & $15^{c}, 15^{d}$ \\
\hline IV & 100 mg pVAX-HSP60 & 42 & Thigh muscle & 12 & 3 & $15^{c}, 15^{d}$ \\
\hline
\end{tabular}

${ }^{a}$ Blood samples from 3 mice per group were collected to assess humoral immunity $(H)$ prior to each immunization and the challenge. ${ }^{b}$ Spleens of the 3 mice per group before challenge were also aseptically removed to assess the cellular immune responses (CIR).

c15 mice per group were intraperitoneally challenged with 1,000 parasites of $T$. gondii RH strain at 14 days after the third immunization.

${ }^{\mathrm{d} A n o t h e r} 15$ mice per group were intragastrically infected with 10 cysts of $T$. gondii PRU strain at 14 days after the third immunization.

any treatment was used as blank control. Three mice each group were handled by ophthalmectomy for accessing humoral immunity, among which spleens of the 3 mice before challenge were also aseptically removed to estimate the cell-mediated immunity such as lymphocyte proliferation, cytokines and flow cytometric analyses.

To further determine whether the immune responses induced by pVAX-HSP60 protect Kunming mice against the acute and chronic Toxoplasma infections, 15 mice in all the groups were intraperitoneally inoculated with 1,000 tachyzoites of RH strain, and their survival time was daily recorded until all the mice were dead. Another 15 mice were challenged with 10 cysts of PRU isolate by oral, and the total number of PRU tissue cysts in their whole brains were counted as the previous description at 30 days post-challenge for evaluating the immune response against the chronic infection (shown in Table 1) [13]. All the experimental and blank control samples were analyzed in triplicate.

\section{Antibody detection}

SBA Clonotyping ${ }^{\mathrm{TM}}$ System/HRP Kit (Southern Biotech, Birmingham, Alabama, USA) and ELISA plates pre-coated with soluble rHSP60 protein (preserved in our laboratory) were used to determine the levels of specific anti-Toxoplasma antibodies (total IgG, IgG1, and IgG2a) in the serum samples. Reference to the kit instruction, ELISA plates were coated with 1.0 $\mu \mathrm{g}$ rHSP60 protein per well overnight at $4.0^{\circ} \mathrm{C}$, washed with $300 \mu \mathrm{l}$ of PBS containing $0.05 \%$ Tween 20 (PBST) per well for 3 times and subsequently blocked with $100 \mu \mathrm{l}$ of $1.0 \% \mathrm{BSA} /$ PBS for $1 \mathrm{hr} .100 \mu \mathrm{l}$ of serum sample was then added to the empty well and incubated at RT for $1 \mathrm{hr}$ with gentle shaking. After washing with PBST, the well was incubated at RT for $1 \mathrm{hr}$ with $100 \mu$ of HRP-conjugated anti-mouse Ig, IgG1 or IgG2a diluted in 1:500, respectively. The color development was per- formed with $100 \mu \mathrm{l}$ of substrate solution containing $1.05 \%$ citric acid, $0.03 \% \mathrm{H}_{2} \mathrm{O}_{2}$ and $0.03 \%$ ABTS provided by the kit. The optical density was measured by ELISA reader (Bio-Tek ELX800, Winooski, Vermont, USA) at $405 \mathrm{~nm}$ after substrate addition according to the manufacturer's instruction.

\section{Flow cytometric analysis}

Spleens of the 3 mice each group were also aseptically removed before challenge, and the single-cell suspensions were prepared using the aseptic wire mesh and erythrocyte lysis solution (Macgene, Beijing, China) [13]. After counting using $0.04 \%$ Trypan Blue dye, $1 \times 10^{5}$ cells in the suspension were diluted in $100 \mu \mathrm{l}$ of $2 \% \mathrm{FBS} / \mathrm{RPMI}-1640$ medium and incubated at $4^{\circ} \mathrm{C}$ for $30 \mathrm{~min}$ in the dark with $0.5 \mu \mathrm{l}$ of PE anti-mouse CD3e, $0.3 \mu$ of APC anti-mouse CD4 and/or $0.2 \mu$ of FITC anti-mouse CD8a (eBioscience, San Diego, California, USA) referring to the manufacturer's guidance. All the samples were washed with $2 \mathrm{ml}$ of PBS, re-suspended with $300 \mu \mathrm{l}$ of FACScan buffer ( $1 \% \mathrm{BSA}, 0.1 \% \mathrm{NaN}_{3}$ ) and fixed with $250 \mu \mathrm{l}$ of $2 \%$ paraformaldehyde. The data were gathered using FACScan flow cytometer (BD Bio-sciences, San Jose, California, USA) and SYSTEM II software (Beckman-Coulter, Miami, Florida, USA). All the samples were carried out in 3 independent experiments.

\section{Cytokine detection and lymphocyte proliferation}

$3 \times 10^{5}$ cells of the single-cell suspension diluted in $200 \mu$ of FBS/RPMI-1640 medium were incubated with $5 \mu \mathrm{g} / \mathrm{ml}$ concanavalin A (ConA, Sigma) at $37^{\circ} \mathrm{C}$ in a $5 \% \mathrm{CO}_{2}$ incubator. The cell-free culture supernatants were collected by centrifugation for $5 \mathrm{~min}$ at 3,000 rpm, and their levels were quantified using pre-coated 96-well plates after 1 day for IL-2 and IL-4, 3 days for IL-10, and 4 days for IL-12p70 and IFN- $\gamma$ according to the manufacturer's instructions (Biolegend, San Diego, Cali- 
fornia, USA). The concentrations of cytokines were calculated referring to the standard curves that were constructed with the known amounts of mouse recombinant IL-2, IL-4, IL-10, IL$12 \mathrm{p} 70$, and IFN- $\gamma$ provided by the kits. The data were harvested from 3 independent experiments.

The same number of single-cell suspension were used for lymphocyte proliferation assay in this study. Briefly, $100 \mu \mathrm{l}$ of lymphocyte solution was spread into 96-well costar plate and subsequently incubated with isometric TLA $(10 \mu \mathrm{g} / \mathrm{ml})$, ConA $(5 \mu \mathrm{g} / \mathrm{ml})$ or medium at $37^{\circ} \mathrm{C}$ in a $5 \% \mathrm{CO}_{2}$ incubator. Evaluation of lymphocyte proliferation was performed using stimulation index (SI) determined by 3-(4,5-dimethylthiazol-2-yl)5-(3-carboxymethoxyphenyl)-2-(4-sulfophenyl)-2H-tetrazolium, inner salt (MTS, $5 \mathrm{mg} / \mathrm{ml}$, Promega) [16]. SI was defined as the ratio of the average absorption value at $570 \mathrm{~nm}$ of wells containing TLA-induced cells $\left(\mathrm{AV}_{\text {TLA }}\right)$ to ConA-induced cells $\left(A V_{C o n A}\right)$ compared to the medium $\left(\mathrm{AV}_{\mathrm{M}}\right)$, respectively. That is, $\mathrm{SI}=\left(\mathrm{AV}_{\mathrm{TLA}} / \mathrm{AV}_{\mathrm{M}}\right) /\left(\mathrm{AV}_{\mathrm{ConA}} / \mathrm{AV}_{\mathrm{M}}\right)$. All the samples were measured in triplicate.

\section{Statistical analysis}

All the measured data were analyzed by SPSS13.0 Data Editor (SPSS Inc., Chicago, IL, USA). Difference between the groups was calculated using student's $t$-test, if their variances analyzed by F-test were equal. A result was considered as different, when $P<0.05$ or significantly different when $P<0.01$.

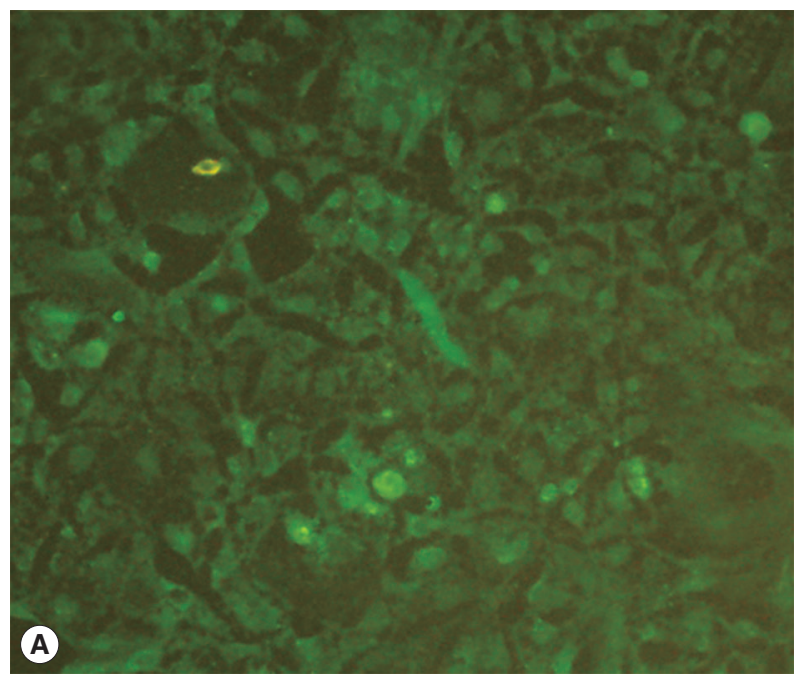

\section{RESULTS}

\section{HSP60 expression in HEK293 cell}

Immunofluorescence assay with goat anti-Toxoplasma antibody was performed to confirm whether pVAX-HSP60 plasmid could be expressed in HEK293 cell in this study, the results of which showed that the specific green fluorescent substances were detected in the cells transfected with pVAXHSP60, but no fluorescence in the control group (shown in Fig. 1), suggesting that Toxoplasma HSP60 recombinant protein can be expressed in eukaryotic cells.

\section{Antibody responses in the immunized mice}

The specific anti-Toxoplasma antibodies (total IgG, IgG1, and IgG2a) in the serum samples were examined through coating with soluble rHSP60 protein and subsequent detection using SBA Clonotyping ${ }^{\mathrm{TM}}$ System/HRP Kit to evaluate the levels of humoral immune responses induced by pVAX-HSP60 immunization. The data showed that the levels of antibodies including total IgG, IgG1, and IgG2a were all significantly elevated in the experimental group in comparison with the control groups (pVAX I, PBS, and blank control) (Fig. 2), and the titers of total IgG in the samples increased with serial pVAX-HSP60 immunizations, suggesting that the humoral and Th1 type immune responses were both elicited.

\section{Cellular immune responses}

Spleen cells in Kunming mice were incubated with ConA,

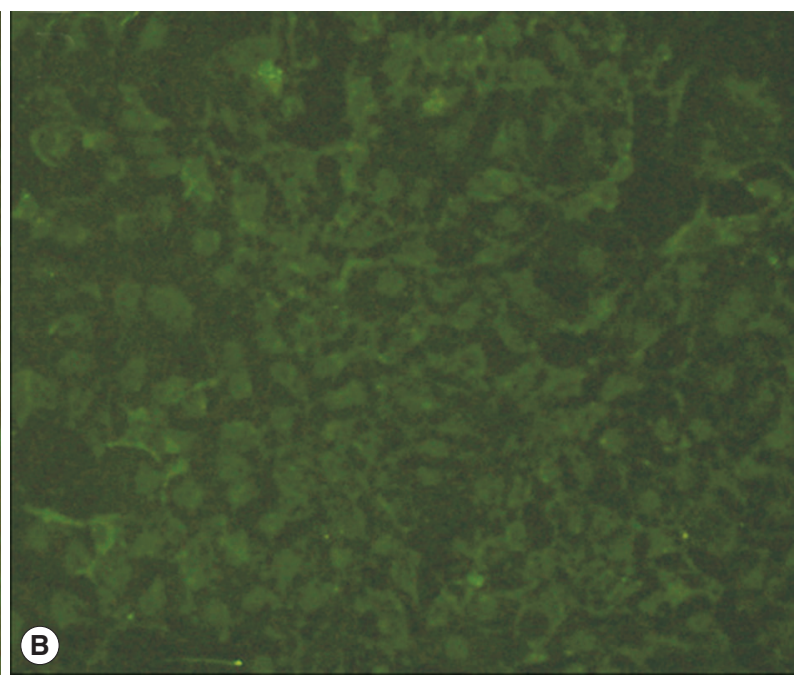

Fig. 1. Immunofluorescence assay for the recombinant HSP60 protein expressed in HEK293 cells. The cells transfected with pVAXHSP60 (A) or with empty pVAXI (B). 

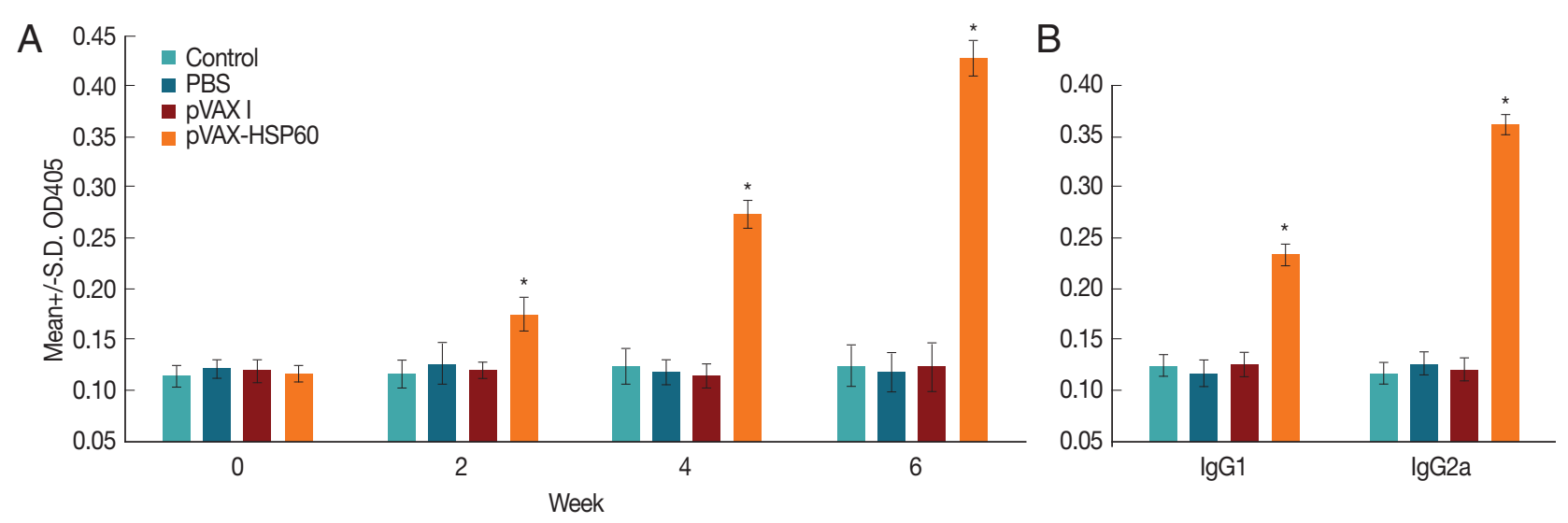

Fig. 2. Determination of antibodies in pVAX-HSP60-immunized Kunming mice. (A) Levels of total lgG antibodies in sera of Kunming mice at 0,2 , and 4 weeks. (B) Titers of IgG subclass in sera of Kunming mice at 14 days after the third immunization. The results are means of OD405 +/- S.D. $(n=3)$. A star (*) denotes $P<0.05$.
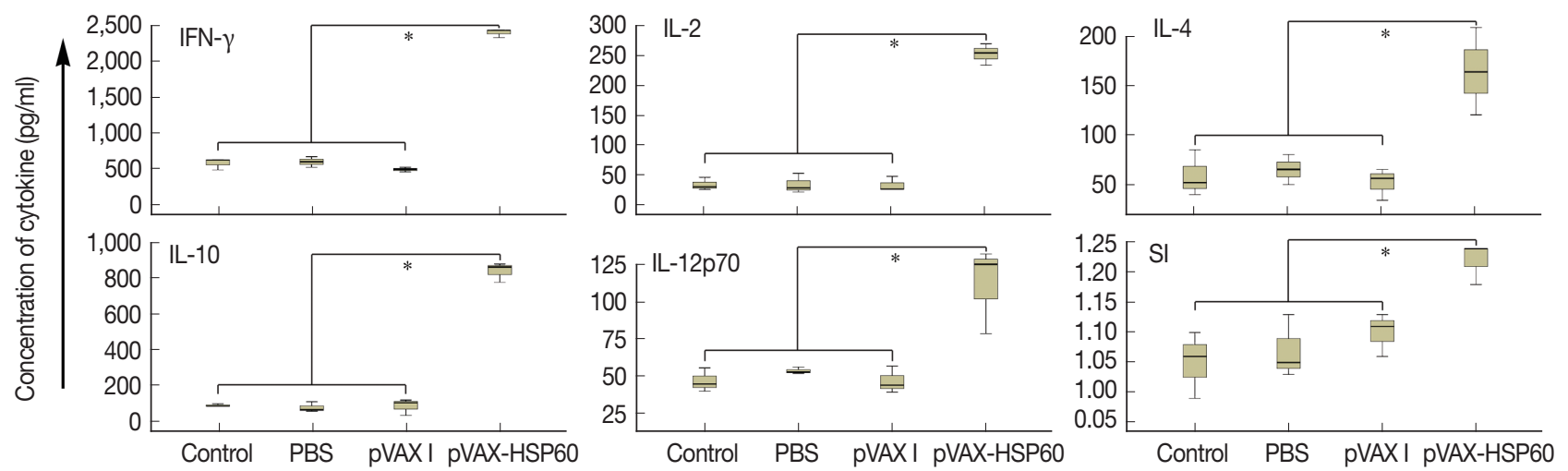

Fig. 3. Cytokine production and SI of splenocytes in the immunized mice. (A) Concentration of cytokines (pg/ml) in the culture supernatants stimulated with concanavalin A. (B) SI of splenocytes induced with concanavalin A and Toxoplasma lysate antigen. ${ }^{\star} P<0.05$.

and 5 kinds of cytokines (IL-2, IL-4, IL-10, IL-12p70, and IFN- $\gamma$ ) were measured in the cell-free culture supernatants. As shown in Fig. 3A, levels of cytokines in group pVAX-HSP60 were all significantly increased in contrast to that of controls $(P<0.05)$.

The proliferation of splenocytes that were separated at 2 weeks after the third immunization was also determined using MTS. The results showed that SI of the mice immunized with pVAX-HSP60 $(1.22 \pm 0.03)$ was significantly higher than that of pVAX I $(1.10 \pm 0.04)$, PBS $(1.07 \pm 0.05)$ and blank control $(1.05 \pm 0.06)(P<0.05)$ (Fig. 3B).

The flow cytometry analyses revealed that the percentages of $\mathrm{CD} 3 \mathrm{e}+\mathrm{CD} 4+$ and $\mathrm{CD} 3 \mathrm{e}+\mathrm{CD} 8 \mathrm{a}+\mathrm{T}$ cells performed as means +/- S.D. were marked (Fig. 4). It was found that CD3e+CD4+ and $\mathrm{CD} 3 e+\mathrm{CD} 8 \mathrm{a}+\mathrm{T}$ cells in pVAX-HSP60-immunized group were significantly increased in comparison to that of controls $(P<0.05)$. It was indicated that Th1- and Th2-type cellular im- mune responses were both triggered through the successive DNA immunizations.

\section{Immune protection against $T$. gondii infections}

To assess whether pVAX-HSP60 immunization could produce immune protections against the acute and chronic Toxoplasma infections, all the groups of Kunming mice were challenged with 1,000 tachyzoites of RH strain or 10 cysts of PRU isolate. The survival times of mice infected with RH parasites were daily recorded until all of them were dead, and significant difference was determined in the mice immunized with pVAX-HSP60 (10.53 \pm 4.78 day) compared to that in groups of pVAX I ( $6.53 \pm 0.64$ day), PBS ( $6.40 \pm 0.63$ day) and blank control (6.33 \pm 0.62 day) $(P<0.05)$ (Fig. 5$)$.

Total number of PRU cysts in whole brain was detected at 30 days post-challenge to evaluate the protective efficacy against the chronic infection of this parasite, the results of 

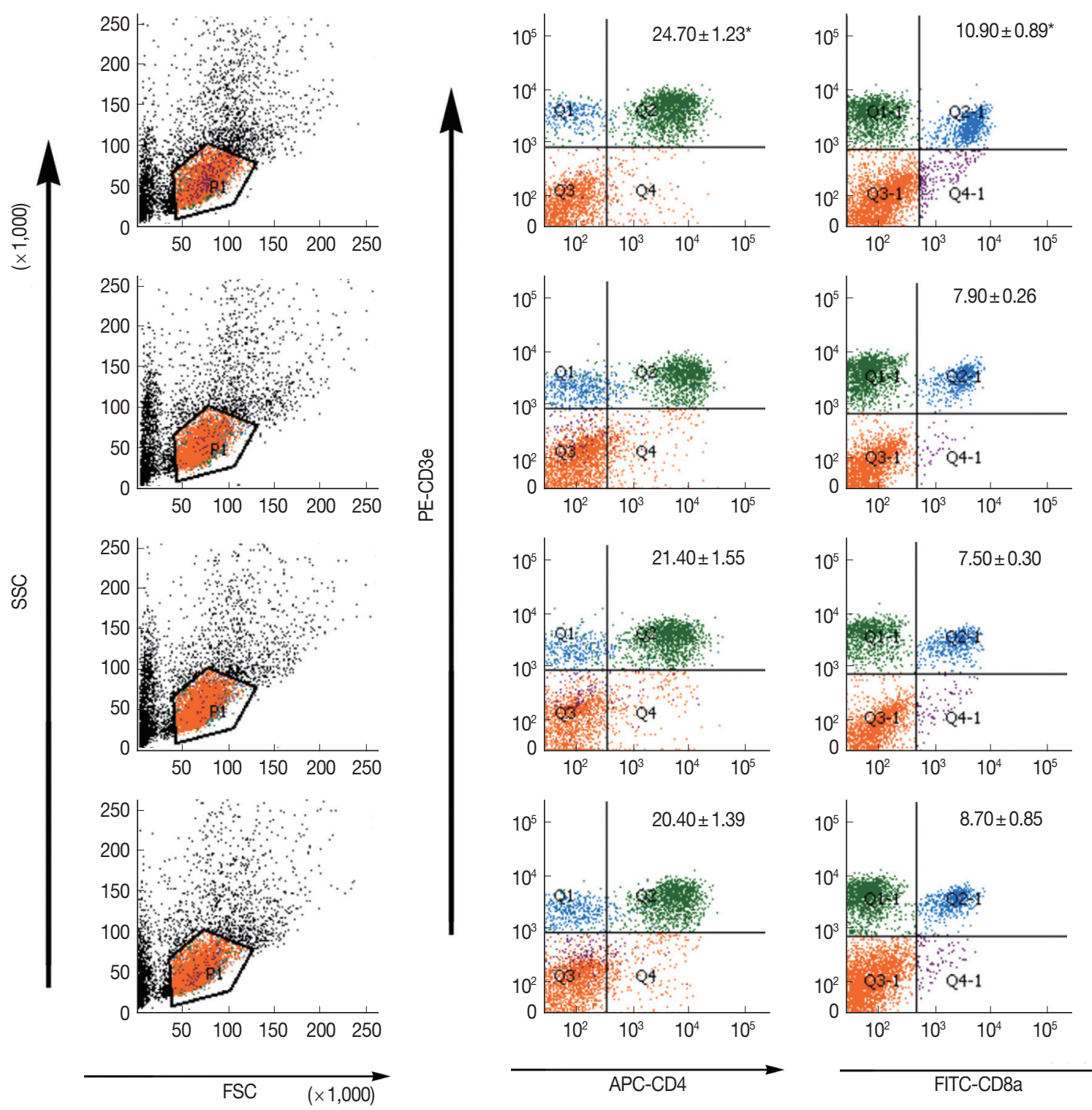

pVAX-HSP60
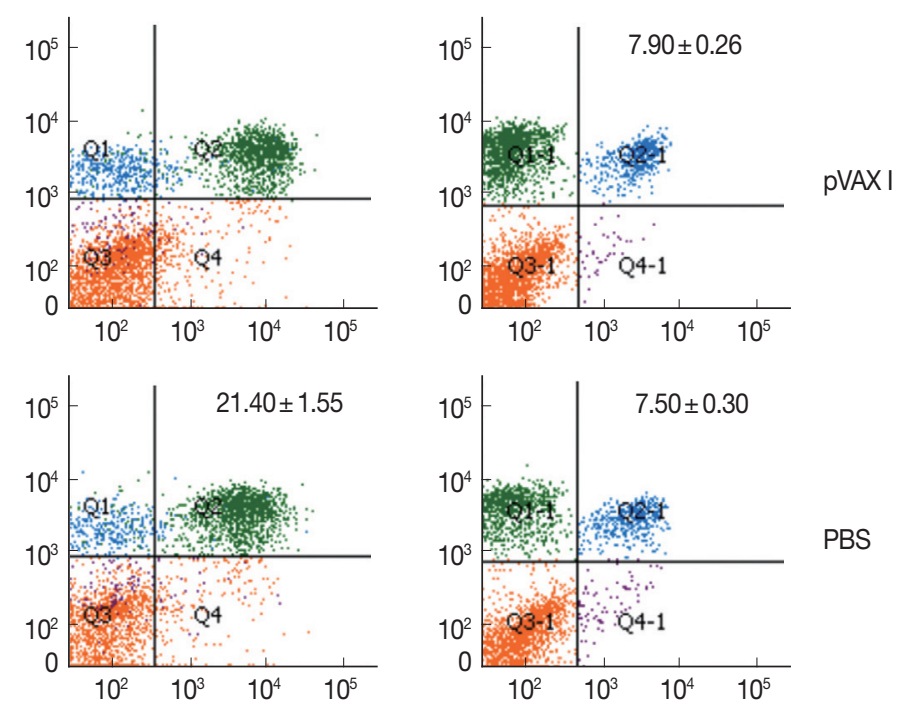

PBS
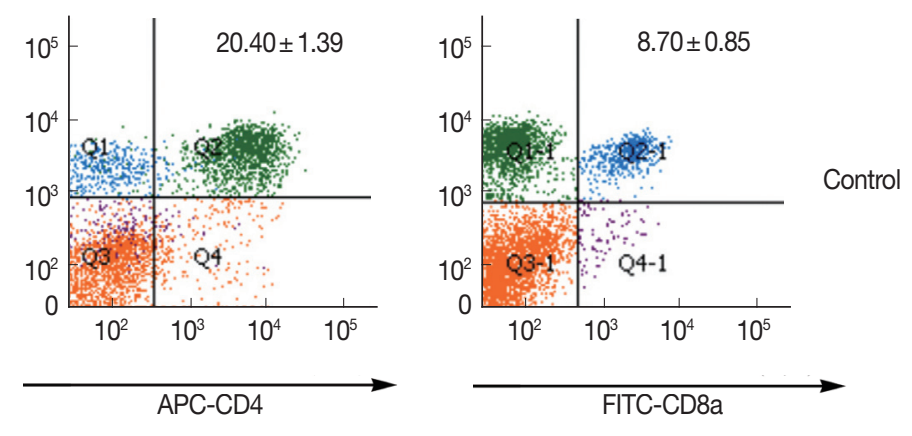

Fig. 4. Determination of lymphocyte subsets in spleen tissues of Kunming mice using flow cytometry. Percentages of CD3e+CD4+ $T$ and CD3e+CD8a+ T cells as means +/- S.D. $(n=3) .{ }^{*} P<0.05$.

which demonstrated that the brain cysts in Kunming mice receiving pVAX-HSP60 immunization were significantly reduced in contrast to that of controls $(P<0.01$; Table 2). Meanwhile, lower but not statistically different cyst loads were detected in other 2 groups (Table 2).

\section{DISCUSSION}

The intracellular protozoan T. gondii with world-wide distribution has deservedly received the basic medical and scientific attentions as it is quite capable of infecting all warm-blooded

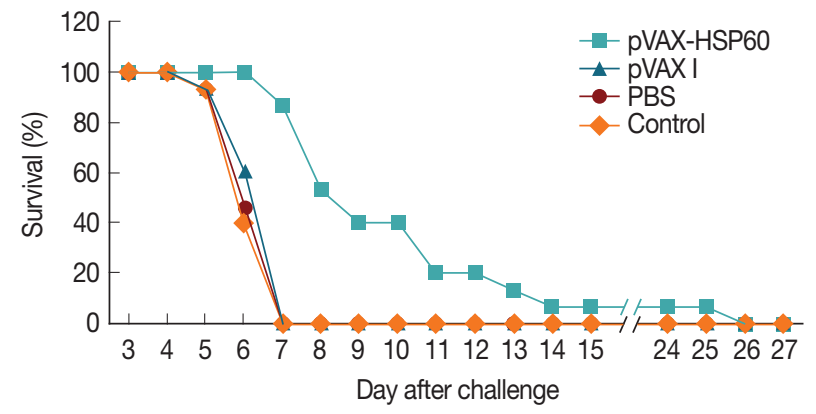

Fig. 5. Survival of Kunming mice vaccinated with pVAX-HSP60 DNA. The mice were challenged with 1,000 tachyzoites of T. gondii $\mathrm{RH}$ strain at 14 days after the third immunization. 
Table 2. Brain cysts in Kunming mouse challenged with 10 cysts of Toxoplasma PRU strain by oral administration

\begin{tabular}{lcc}
\hline Group $(n=15)$ & $\begin{array}{c}\text { Number of brain cysts } \\
(\text { Mean } \pm \text { S.D. })\end{array}$ & \% reduction \\
\hline Control & $3,270.77 \pm 109.06$ & - \\
PBS & $3,022.36 \pm 237.77$ & $7.60 \pm 6.64$ \\
pVAXI & $3,487.17 \pm 183.50$ & $-6.57 \pm 2.03$ \\
pVAX-HSP60 & $1,705.68 \pm 139.39^{\star}$ & $47.84 \pm 4.09^{\star}$ \\
\hline
\end{tabular}

*Statistically significant difference between pVAX-HSP60-immunized mice and control groups, $P<0.01$.

animals from avian to mammals and leads to serious congenital diseases, abortion in pregnant women and domestic animals, and Toxoplasma encephalitis in immunocompromised individuals etc. [17-19]. In consideration of no ideal medicines for the clinical therapy so far, a safe and effective countermeasure should be forwardly executed to restrict the spreading and development of this parasite [3].

In the last several years, many attempts including subunit and live-attenuated Toxoplasma strain vaccines have been made, but not feasible because of their unsatisfactory effects, expensiveness and short shelf life $[20,21]$. Thus the exploration of DNA vaccine has been focused under the current efforts [22,23]. In addition, the previous reports have demonstrated that DNAembarked vaccines possessed the articulated skeleton of pVAX I vector are able to express various genes in eukaryotic cells such as Marc-145 and HEK293, and trigger strong humoral and cellular immune responses $[24,25]$. Therefore, the effective eukaryotic system based on pVAX I skeleton was used in this study to express the HSP60 protein of T. gondii, and its fairly strong transcription in eukaryotic cells was further demonstrated using immunofluorescence assay.

As described previously, the innate and adaptive immune responses in hosts can be both induced for resistance to toxoplasmosis during the natural invasion and artificial injection of T. gondii [26]. In addition, this parasite is capable of activating a strong Th1-type cellular immune response to protect Toxoplasma-infected host against acute death, characterized by the release of early IL-12 and IFN- $\gamma$ [27]. Hence, 5 kinds of cytokines besides IL-12p70 and IFN- $\gamma$ in the spleen cell-free culture supernatants, which are compactly connected with the innate immune response, were measured in the present study through stimulation with ConA [28]. The results showed that all the examined cytokines (IFN- $\gamma$, IL-2, IL-4, IL-10, and IL12p70) in the pVAX-HSP60-immunized mice increased highly in contrast to that of the 3 controls, indicating that the innate immune response was significantly awakened via serial DNA immunizations.

As the important index of adaptive immune response during Toxoplasma infection, the titers of specific antibodies in serum were used to evaluate the development of toxoplasmosis for a long time [29]. Based on this consideration, total IgG, $\operatorname{IgG} 1$ and $\mathrm{IgG} 2 \mathrm{a}$ in the mice were detected by coated with the soluble rHSP60 protein that was preserved in our laboratory. Our data showed that levels of specific antibodies in sera were all significantly elevated in the mice receiving DNA immunizations compared to the 3 controls, indicating that the successive pVAX-HSP60 stimuli triggered strong humoral immune responses in Kunming mice.

Moreover, several parameters of cellular immune responses were detected to further explore the elements beneficial for host against Toxoplasma acute and chronic infections in the study, and the proliferation of T lymphocytes separated from spleen tissues in the mice receiving pVAX-HSP60 immunization was determined using flow cytometry and MTS analyses, with the significant increase of $\mathrm{CD} 3 e+C D 4+$ and $\mathrm{CD} 3 e+C D 8 a+$ $\mathrm{T}$ cells and the significantly elevated stimulation index in comparison with the controls, matching with the previous reports $[13,30]$, which indicated that the cellular immune responses of Kunming mice were also evoked by immunization with pVAX-HSP60.

To assess whether the innate and adaptive immune responses stimulated by pVAX-HSP60 were beneficial for the resistance to toxoplasmosis, the residual Kunming mice were finally challenged with 1,000 tachyzoites of RH strain through intraperitoneal injection or 10 cysts of PRU isolate orally, and their survival times or reduction of brain cysts were examined in the end of all the experiments. We found that the immunizations with pVAX-HSP60 were able to significantly prolong the survival times and reduce the number of brain cysts in contrast to that in control groups. As the deficiencies of the single-gene vaccines do exist such as the incomplete protection, the exploitation of ideal vaccines against $T$. gondii infection will still be going on.

In conclusion, high humoral and cellular immune responses were induced byHSP60 DNA immunization, which were a main reason resulting in protection against $T$. gondii infections. It was suggested that HSP60 DNA can be a vaccine candidate to control and prevent spreading of T. gondii infections. 


\section{ACKNOWLEDGMENTS}

This project support was provided, in part, by the General Financial Grant from the China Postdoctoral Science Foundation (Grant No. 2017M612056), the Open Funds of the State Key Laboratory of Veterinary Etiological Biology (Grant No. SKLVEB2016KFKT015) and the Agricultural Science and Technology Innovation Program (ASTIP) (Grant No. CAAS-ASTIP2016-LVRI-03).

\section{CONFLICT OF INTEREST}

The authors declare that they have no conflicts of interests.

\section{REFERENCES}

1. Barratt JL, Harkness J, Marriott D, Ellis JT, Stark D. Importance of nonenteric protozoan infections in immunocompromised people. Clin Microbiol Rev 2010; 23: 795-836.

2. Giakoumelou S, Wheelhouse N, Cuschieri K, Entrican G, Howie $\mathrm{SE}$, Horne AW. The role of infection in miscarriage. Hum Reprod Update 2016; 22: 116-133.

3. Alday PH, Doggett JS. Drugs in development for toxoplasmosis: advances, challenges, and current status. Drug Des Devel Ther 2017; 11: 273-293.

4. Mattoo RU, Goloubinoff P. Molecular chaperones are nanomachines that catalytically unfold misfolded and alternatively folded proteins. Cell Mol Life Sci 2014; 71: 3311-3325.

5. Finka A, Sharma SK, Goloubinoff P. Multi-layered molecular mechanisms of polypeptide holding, unfolding and disaggregation by HSP70/HSP110 chaperones. Front Mol Biosci 2015; 2: 29.

6. Bar-Lavan Y, Shemesh N, Ben-Zvi A. Chaperone families and interactions in metazoa. Essays Biochem 2016; 60: 237-253.

7. Binder RJ. Functions of heat shock proteins in pathways of the innate and adaptive immune system. J Immunol 2014; 193: 57655771.

8. Juwono J, Martinus RD. Does hsp60 provide a link between mitochondrial stress and inflammation in diabetes mellitus? J Diabetes Res 2016; 2016: 8017571.

9. Wu J, Liu T, Rios Z, Mei Q, Lin X, Cao S. Heat shock proteins and cancer. Trends Pharmacol Sci 2017; 38: 226-256.

10. Toursel C, Dzierszinski F, Bernigaud A, Mortuaire M, Tomavo S. Molecular cloning, organellar targeting and developmental expression of mitochondrial chaperone HSP60 in Toxoplasma gondii. Mol Biochem Parasitol 2000; 111: 319-332.

11. Ma GY, Zhang JZ, Yin GR, Zhang JH, Meng XL, Zhao F. Toxoplasma gondii: proteomic analysis of antigenicity of soluble tachyzoite antigen. Exp Parasitol 2009; 122: 41-46.

12. Wang F, Liu F, Liu H, Chen W, Si X, Ma X. Effects of immunolog- ical and hematological parameter in mice exposed to mixture of volatile organic compounds. Inhal Toxicol 2016; 28: 164-169.

13. Li ZY, Chen J, Petersen E, Zhou DH, Huang SY, Song HQ, Zhu XQ. Synergy of mIL-21 and mIL-15 in enhancing DNA vaccine efficacy against acute and chronic Toxoplasma gondii infection in mice. Vaccine 2014; 32: 3058-3065.

14. Zhang NZ, Xu Y, Wang M, Petersen E, Chen J, Huang SY, Zhu $X Q$. Protective efficacy of two novel DNA vaccines expressing Toxoplasma gondii rhomboid 4 and rhomboid 5 proteins against acute and chronic toxoplasmosis in mice. Expert Rev Vaccines 2015; 14: 1289-1297.

15. Yuan ZG, Ren D, Zhou DH, Zhang XX, Petersen E, Li XZ, Zhou Y, Yang GL, Zhu XQ. Evaluation of protective effect of pVAX-TgMIC13 plasmid against acute and chronic Toxoplasma gondii infection in a murine model. Vaccine 2013; 31: 3135-3139.

16. Ota $Y$, Ishihara $S$, Otani K, Yasuda K, Nishikawa T, Tanaka T, Tanaka J, Kiyomatsu T, Kawai K, Hata K, Nozawa H, Kazama S, Yamaguchi H, Sunami E, Kitayama J, Watanabe T. Effect of nutrient starvation on proliferation and cytokine secretion of peripheral blood lymphocytes. Mol Clin Oncol 2016; 4: 607-610.

17. Kur J, Holec-Gasior L, Hiszczyńska-Sawicka E. Current status of toxoplasmosis vaccine development. Expert Rev Vaccines 2009; 8: 791-808.

18. Weiss LM, Dubey JP. Toxoplasmosis: A history of clinical observations. Int J Parasitol. 2009; 39: 895-901.

19. Yarovinsky F. Innate immunity to Toxoplasma gondii infection. Nat Rev Immunol 2014; 14: 109-121.

20. Burrells A, Benavides J, Cantón G, Garcia JL, Bartley PM, Nath M, Thomson J, Chianini F, Innes EA, Katzer F. Vaccination of pigs with the S48 strain of Toxoplasma gondii--safer meat for human consumption. Vet Res 2015; 46: 47.

21. Ching XT, Fong MY, Lau YL. Evaluation of immunoprotection conferred by the subunit vaccines of GRA2 and GRA5 against acute toxoplasmosis in BALB/c mice. Front Microbiol 2016; 7: 609.

22. Li L, Petrovsky N. Molecular mechanisms for enhanced DNA vaccine immunogenicity. Expert Rev Vaccines 2016; 15: 313-329.

23. Han Y, Zhou A, Lu G, Zhao G, Sha W, Wang L, Guo J, Zhou J, Zhou H, Cong H, He S. DNA vaccines encoding Toxoplasma gondii cathepsin $\mathrm{C} 1$ induce protection against toxoplasmosis in mice. Korean J Parasitol 2017; 55: 505-512.

24. Chen J, Huang SY, Zhou DH, Li ZY, Petersen E, Song HQ, Zhu XQ. DNA immunization with eukaryotic initiation factor-2 $\alpha$ of Toxoplasma gondii induces protective immunity against acute and chronic toxoplasmosis in mice. Vaccine 2013; 31: 6225-6231.

25. Xu Y, Zhang NZ, Tan QD, Chen J, Lu J, Xu QM, Zhu XQ. Evaluation of immuno-efficacy of a novel DNA vaccine encoding Toxoplasma gondii rhoptry protein 38 (TgROP38) against chronic toxoplasmosis in a murine model. BMC Infect Dis 2014; 14: 525.

26. Dupont CD, Christian DA, Hunter CA. Immune response and immunopathology during toxoplasmosis. Semin Immunopathol 2012; 34: 793-813.

27. Gazzinelli RT, Wysocka M, Hayashi S, Denkers EY, Hieny S, Cas- 
par P, Trinchieri G, Sher A. Parasite-induced IL-12 stimulates early IFN-gamma synthesis and resistance during acute infection with Toxoplasma gondii. J Immunol 1994; 153: 2533-2543.

28. Carter CJ. Schizophrenia susceptibility genes directly implicated in the life cycles of pathogens: cytomegalovirus, influenza, herpes simplex, rubella, and Toxoplasma gondii. Schizophr Bull 2009; 35:
1163-1182.

29. Davidson MG. Toxoplasmosis. Vet Clin North Am Small Anim Pract 2000; 30: 1051-1062.

30. Koliński T, Marek-Trzonkowska N, Trzonkowski P, Siebert J. Heat shock proteins (HSPs) in the homeostasis of regulatory T cells (Tregs). Cent Eur J Immunol 2016; 41: 317-323. 
